\title{
Risk factors for lymph node metastasis in gastric neuroendocrine tumor: a retrospective study
}

Xianghui $\mathrm{Li}^{1 \dagger}$, Lihua Shao ${ }^{1 \dagger}$, Xiaofeng $\mathrm{Lu}^{1 \dagger}$, Zhengyang Yang ${ }^{2}$, Shichao Ai ${ }^{1}$, Feng Sun ${ }^{1}$, Meng Wang ${ }^{{ }^{*}}$, Wenxian Guan ${ }^{1 *}$ and Song Liu ${ }^{1 *}$

\begin{abstract}
Background: Lymph node metastasis (LNM) plays a vital role in the determination of clinical outcomes in patients with gastric neuroendocrine tumor (G-NET). Preoperative identification of LNM is helpful for intraoperative lymphadenectomy. This study aims to investigate risk factors for LNM in patients with G-NET.

Methods: We performed a retrospective study involving 37 patients in non-LNM group and 82 patients in LNM group. Data of demographics, preoperative lab results, clinical-pathological results, surgical management, and postoperative situation were compared between groups. Significant parameters were subsequently entered into logistic regression for further analysis.
\end{abstract}

Results: Patients in LNM group exhibited older age $(p=0.011)$, lower preoperative albumin (ALB) $(p=0.003)$, higher carcinoembryonic antigen (CEA) $(p=0.020)$, higher International normalized ratio $(p=0.034)$, longer thrombin time $(p=0.018)$, different tumor location $(p=0.005)$, higher chromogranin A positive rate $(p=0.045)$, and higher Ki-67 expression level $(p=0.002)$. Logistic regression revealed ALB $(p=0.043)$, CEA $(p=0.032)$, tumor location $(p=0.013)$ and Ki-67 ( $p=0.041$ ) were independent risk factors for LNM in G-NET patients.

Conclusions: ALB, CEA, tumor location, and Ki-67 expression level correlate with the risk of LNM in patients with G-NET.

Keywords: Gastric neuroendocrine tumor, Lymph node metastasis, Risk factors

\section{Background}

Gastric neuroendocrine tumors (G-NET) formed by heterogeneous neoplasms arising from secretory cells of diffuse neuroendocrine system in stomach, one of the most common pathogenic site. Though G-NET is rare with a

\footnotetext{
*Correspondence: 5545840@qq.com; quan_wenxian@sina.com; liusong@njglyy.com

${ }^{+}$Xianghui Li, Lihua Shao, and Xiaofeng Lu contributed equally to this work

${ }^{1}$ Department of Gastrointestinal Surgery, Nanjing Drum Tower Hospital, The Affiliated Hospital of Nanjing University Medical School, 321 Zhongshan RD, Nanjing 210008, China

Full list of author information is available at the end of the article
}

$1 \sim 2 / 1,000,000$ incidence which accounts for $6.9 \sim 8.7 \%$ of all digestive neuroendocrine neoplasms per year, its incidence is increasing during recent decades worldwide [1-4]. Surgery serves as the first-line strategy for the management of G-NET [5]. Lymphadenectomy is required in patients with lymph node metastasis (LNM) for the prevention of recurrence and metastasis. Moreover, the rate of LNM in G-NET is higher than that in gastric adenocarcinoma [6]. Therefore, preoperative risk evaluation, diagnosis, and management of LNM in G-NET have become challenging issues.

World Health Organization (WHO) revised G grade in neuroendocrine tumors in 2010, in which G stands 
for grading according to mitotic count and $\mathrm{Ki}-67$ index. The classifications and site-specific staging systems are mainly based on clinical pathology and immunohistochemistry, which provides limited information on LNM. Evidence regarding the preoperative identification of LNM in neuroendocrine tumors is very limited in current literature. In this circumstance, we aim to explore independent risk factors for LNM in patients with G-NET.

\section{Methods}

\section{Patient selection}

Between 2012 and 2019, all patients with G-NET that registered in Gastrointestinal Surgery of our hospital were recruited for qualification screening. The inclusion criteria were as follows: (1) definitive pathological diagnosis of G-NET; (2) the availability of pathological report; (3) absence of preoperative treatment including chemotherapy and radiotherapy. All patients in this study received D2 lymphectomy.

\section{Data collection}

Data including demographics, preoperative lab results, clinical-pathological results, surgical management, and postoperative outcome were retrieved from the Electronic Medical Record System. Demographics included sex, age, underlying disease, past abdominal surgical history, and chief complaint. Preoperative lab result consisted of white blood cell count, neutrophil cell count, lymphocyte count, monocyte count, hemoglobin, platelet, albumin (ALB), C-reactive protein (CRP) levels, neutrophil-to-lymphocyte ratio (NLR), platelet-to-lymphocyte ratio (PLR), Onodera prognostic nutrition index (OPNI), fecal occult blood test, carcinoembryonic antigen (CEA), alpha-fetoprotein (AFP), CA125, CA199, CA242, CA724, international normalized ratio (INR), activated partial thromboplastin time (APTT), prothrombin time (PT) and thrombin time (TT). All these results were recorded from the last test before surgery. Clinical pathological results included lymph node metastasis, total number of resected lymph nodes, tumor size, tumor location, CD56, tumor proliferation index (Ki67), synaptophysin (Syn), and Chromogranin A (CgA). Surgical management included type of surgical procedure, duration of operation and intraoperative hemorrhage. Postoperative outcomes consisted of postoperative hospitalization time, postoperative oral feeding time and postoperative complications. All enrolled patients were divided into LNM group or non-LNM group according to the postoperative pathological report.

\section{Statistical analysis}

All analyses were 2-tailed. The confidence interval was $5 \sim 95 \%$, and p-values $<0.05$ were defined as statistically significant. For continuous variables, data were presented as the mean $\pm S D$ (standard deviation), and unpaired t-test with Welch's correction was applied for statistical analysis. For categorical variables, data were presented as frequency (percentage), and Chi-square test with Fisher's exact test was conducted for statistical analysis. Significant variables in univariate analysis were brought into binary logistic regression model for multivariate analysis. And predicted risk factors were brought into receiver operation characteristic (ROC) curve analysis. All statistical analyses were performed in SPSS software (version 23.0; IBM Inc., Chicago, IL) and MedCalc software (version 11.4.2; MedCalc Software, Ostend, Belgium).

\section{Results}

Between 2012 and 2019, a total of 122 G-NET patients that received surgery in our department were enrolled. According to the pathological report, 37 patients formed the non-LNM group, 82 patients formed the LNM group, and the other 3 patients were excluded due to the unavailability of lymph node information in pathological reports.

Table 1 compared demographics between two groups. Patients in LNM group were older than those in LNM group $(p=0.011)$. However, the difference in gender, hypertension, diabetes, other underlying diseases, past abdominal surgical history and chief complaint between two groups were not significant.

As showed in Table 2, higher ALB was observed in nonLNM group $(p=0.003)$, whereas higher INR $(p=0.034)$, longer TT $(p=0.018)$ and higher CEA $(p=0.020)$ were

Table 1 Demographics of patients between non-LNM and LNM groups

\begin{tabular}{llll}
\hline & $\begin{array}{l}\text { Non-LNM } \\
(n=37)\end{array}$ & $\begin{array}{l}\text { LNM } \\
(n=82)\end{array}$ & P-value \\
\hline Male $(n, \%)$ & $24(64.9 \%)$ & $60(83.2 \%)$ & 0.357 \\
Age (median \pm SD) & $61.22 \pm 10.27$ & $66.09 \pm 9.16$ & $0.011^{*}$ \\
Hypertension $(n, \%)$ & $11(31.4 \%)$ & $23(28.8 \%)$ & 0.772 \\
Diabetes $(n, \%)$ & $2(5.7 \%)$ & $8(10.0 \%)$ & 0.696 \\
Other background disease $(n, \%)$ & $2(5.9 \%)$ & $6(7.7 \%)$ & 0.732 \\
Past abdominal surgery $(n, \%)$ & $8(22.9 \%)$ & $21(26.2 \%)$ & 0.700 \\
Chief complaint & & & 0.410 \\
Health examination & $2(5.7 \%)$ & $4(5.0 \%)$ & - \\
Pain & $20(57.1 \%)$ & $35(43.8 \%)$ & - \\
Melena/ hematemesis & $4(11.4 \%)$ & $13(16.2 \%)$ & - \\
Abdominal discomfort & $9(25.7 \%)$ & $22(27.5 \%)$ & - \\
\hline
\end{tabular}

* The asterisk indicates statistical significance 
Table 2 Preoperative lab test between patients in non-LNM and LNM groups

\begin{tabular}{|c|c|c|c|}
\hline & $\begin{array}{l}\text { Non-LNM } \\
(n=37)\end{array}$ & $\begin{array}{l}\text { LNM } \\
(n=82)\end{array}$ & P-value \\
\hline WBC $\left(\times 10^{9} / \mathrm{L}\right)$ & $5.64 \pm 1.55$ & $6.35 \pm 2.38$ & 0.097 \\
\hline Neutrophils (× 109/L) & $3.53 \pm 1.24$ & $3.92 \pm 2.13$ & 0.307 \\
\hline Lymphocytes $\left(\times 10^{9} / \mathrm{L}\right)$ & $1.56 \pm 0.50$ & $1.52 \pm 0.61$ & 0.749 \\
\hline Monocytes $\left(\times 10^{9} / \mathrm{L}\right)$ & $0.69 \pm 1.39$ & $0.52 \pm 0.75$ & 0.412 \\
\hline $\mathrm{Hb}(\mathrm{g} / \mathrm{L})$ & $121.43 \pm 26.31$ & $114.01 \pm 25.61$ & 0.150 \\
\hline $\operatorname{PLT}\left(\times 10^{9} / \mathrm{L}\right)$ & $236.84 \pm 85.12$ & $228.91 \pm 87.55$ & 0.646 \\
\hline ALB $(g / L)$ & $39.93 \pm 4.71$ & $36.63 \pm 5.69$ & $0.003^{*}$ \\
\hline CRP (mg/L) & $8.18 \pm 14.88$ & $16.70 \pm 32.75$ & 0.134 \\
\hline NLR & $2.41 \pm 0.88$ & $3.00 \pm 2.81$ & 0.226 \\
\hline PLR & $159.63 \pm 58.80$ & $165.78 \pm 101.28$ & 0.739 \\
\hline OPNI & $46.03 \pm 9.78$ & $43.54 \pm 8.54$ & 0.166 \\
\hline Fecal occult blood test $(n, \%)$ & & & 0.428 \\
\hline Negative & $28(75.7 \%)$ & $56(68.3 \%)$ & - \\
\hline Positive & $4(10.8 \%)$ & $13(15.9 \%)$ & - \\
\hline Unknown & $5(13.5 \%)$ & $13(15.9 \%)$ & - \\
\hline AFP (ng/ml) & $9.90 \pm 27.94$ & $5.30 \pm 18.41$ & 0.320 \\
\hline CEA (ng/ml) & $2.41 \pm 3.29$ & $12.25 \pm 23.78$ & $0.020^{*}$ \\
\hline CA125 (U/ml) & $23.84 \pm 68.17$ & $13.05 \pm 15.03$ & 0.203 \\
\hline CA199 (U/ml) & $9.29 \pm 7.14$ & $27.82 \pm 96.43$ & 0.274 \\
\hline CA242 (U/ml) & $4.05 \pm 3.16$ & $6.60 \pm 9.92$ & 0.213 \\
\hline CA724 (U/ml) & $2.18 \pm 3.56$ & $6.88 \pm 23.36$ & 0.312 \\
\hline INR & $1.01 \pm 0.77$ & $1.04 \pm 0.78$ & $0.034^{*}$ \\
\hline APPT (s) & $26.41 \pm 5.10$ & $28.25 \pm 5.30$ & 0.081 \\
\hline PT (s) & $17.66 \pm 3.31$ & $18.32 \pm 1.85$ & 0.171 \\
\hline $\mathrm{TT}(\mathrm{s})$ & $11.53 \pm 0.87$ & $11.96 \pm 0.94$ & $0.018^{*}$ \\
\hline
\end{tabular}

* The asterisk indicates statistical significance

observed in LNM group. The differences of routine preoperative blood test, tumor biomarkers and other lab tests were not significant between groups. Especially, G grade was not significantly related to LNM.

The distribution of tumor location was different between non-LNM and LNM groups $(p=0.005)$, although the tumor in both groups preferred cardia and fundus of stomach. Besides, higher Ki-67 index $(p=0.002)$ and higher CgA positive rate $(p=0.045)$ were found in LNM group (Table 3).

There was no statistical difference in surgical procedure, duration of operation, intraoperative hemorrhage, postoperative hospitalization, postoperative oral feeding and postoperative complications between two groups (Table 4). A certain proportion of patients were transferred into ICU after surgery $(38.5 \%$ and $32.9 \%$ in two groups, respectively). The ICU stay is mostly 1 day for patients in both groups (Table 4).

Binary logistic regression was further conducted. Significant variables identified in previous univariate analysis (including age, ALB, CEA, INR, TT, tumor location,
Table 3 Tumor characteristics of patients between non-LNM and LNM groups

\begin{tabular}{|c|c|c|c|}
\hline & $\begin{array}{l}\text { Non-LNM } \\
(n=37)\end{array}$ & $\begin{array}{l}\text { LNM } \\
(n=82)\end{array}$ & P-value \\
\hline Tumor size (cm) & $4.44 \pm 3.81$ & $5.37 \pm 2.54$ & 0.120 \\
\hline Tumor size classification (n, \%) & & & 0.062 \\
\hline$<5 \mathrm{~cm}$ & $27(73.0 \%)$ & 45 (54.9\%) & - \\
\hline$\geq 5 \mathrm{~cm}$ & $10(27.0 \%)$ & $37(45.1 \%)$ & - \\
\hline G grade (n, \%) & & & 0.210 \\
\hline G1 & $3(8.3 \%)$ & $5(6.1 \%)$ & - \\
\hline G2 & $0(0.0 \%)$ & $4(4.88 \%)$ & - \\
\hline G3 & $22(61.1 \%)$ & $59(72.0 \%)$ & - \\
\hline NEC & $11(30.6 \%)$ & $14(17.1 \%)$ & - \\
\hline Tumor location (n, \%) & & & $0.005^{*}$ \\
\hline Cardia and fundus of stomach & $16(43.2 \%)$ & $46(56.3 \%)$ & - \\
\hline Body of stomach & $9(24.3 \%)$ & $30(36.6 \%)$ & - \\
\hline Pyloric antrum & $7(18.9 \%)$ & $5(6.5 \%)$ & - \\
\hline Pyloric canal & $5(13.5 \%)$ & $1(1.2 \%)$ & - \\
\hline CD56 $(n, \%)$ & & & 0.177 \\
\hline- & $9(27.3 \%)$ & $15(21.9 \%)$ & - \\
\hline+ & $12(36.4 \%)$ & $32(46.4 \%)$ & - \\
\hline++ & $8(24.2 \%)$ & $7(10.1 \%)$ & - \\
\hline+++ & $4(12.1 \%)$ & $15(21.7 \%)$ & - \\
\hline Unknown & $4(12.1 \%)$ & $13(15.9 \%)$ & - \\
\hline Ki67 & $43.3 \pm 27.6 \%$ & $58.3 \pm 21.6 \%$ & $0.002^{*}$ \\
\hline Syn (n, \%) & & & 0.405 \\
\hline- & 0 & $1(1.2 \%)$ & - \\
\hline+ & $14(37.8 \%)$ & $22(26.8 \%)$ & - \\
\hline++ & $5(13.5 \%)$ & 20 (24.4\%) & - \\
\hline+++ & 17 (45.9\%) & 37 (45.1\%) & - \\
\hline Unknown & $1(2.7 \%)$ & $2(2.4 \%)$ & - \\
\hline $\mathrm{CgA}(\mathrm{n}, \%)$ & & & $0.045^{*}$ \\
\hline- & $9(24.4 \%)$ & 22 (26.8\%) & - \\
\hline+ & $14(37.8 \%)$ & 31 (37.8\%) & - \\
\hline++ & 0 & 11 (13.4\%) & - \\
\hline+++ & $13(35.1 \%)$ & 15 (18.3\%) & - \\
\hline Unknown & $1(2.7 \%)$ & $3(3.7 \%)$ & - \\
\hline
\end{tabular}

"The asterisk indicates statistical significance

Ki67 and CgA) were enrolled into the regression model. ALB $(\mathrm{p}=0.004)$, CEA $(\mathrm{p}<0.001)$, tumor location $(p=0.006)$ and $\operatorname{Ki67}(p=0.041)$ were statistically significant between non-LNM and LNM groups (Table 5).

Subsequent ROC analysis calculated the diagnostic value of each risk factor. The AUC area for ALB, CEA, tumor location and Ki-67 was 0.707, 0.642, 0.618 and 0.657 , respectively. Integration of all risk factors exerts a better diagnostic capacity (AUC $=0.779,95 \%$ $\mathrm{CI}=0.688 \sim 0.855, \mathrm{p}<0.0001$ ) (Fig. 1). These data generated a proposed approach for the risk evaluation of lymph node metastasis in G-NET (Fig. 2). 
Table 4 Surgical procedures and outcome between patients in non-LNM and LNM groups

\begin{tabular}{llll}
\hline & $\begin{array}{l}\text { Non-LNM } \\
(\mathrm{n}=37)\end{array}$ & $\begin{array}{l}\text { LNM } \\
(\mathrm{n}=82)\end{array}$ & P-value \\
\hline $\begin{array}{l}\text { Surgical procedure } \\
\text { Local resection }\end{array}$ & $2(5.4 \%)$ & $1(1.2 \%)$ & 0.119 \\
Distal gastrectomy & $9(24.3 \%)$ & $9(11.0 \%)$ & - \\
Proximal gastrectomy & $6(16.2 \%)$ & $13(15.9 \%)$ & - \\
$\quad$ Total gastrectomy & $20(54.1 \%)$ & $59(72.6 \%)$ & - \\
Duration of operation (min) & $225.97 \pm 84.84$ & $239.83 \pm 71.07$ & 0.367 \\
Intraoperative hemorrhage (ml) & $338.57 \pm 541.93$ & $260.13 \pm 259.23$ & $13.49 \pm 5.44$ \\
Postoperative hospitalization (d) & $14.97 \pm 10.16$ & $7.61 \pm 2.91$ & 0.303 \\
Postoperative oral feeding (d) & $9.09 \pm 6.46$ & $1(1.2 \%)$ & 0.311 \\
Postoperative complications $(\mathrm{n}, \%)$ & $1(2.7 \%)$ & $27(32.9 \%)$ & 0.093 \\
ICU stay (n, \%) & $15(38.5 \%)$ & 0.509 \\
\hline
\end{tabular}

Table 5 Logistic regression analysis of risk factors for lymph node metastasis in G-NET

\begin{tabular}{lclc}
\hline & OR & $95 \% \mathrm{Cl}$ & P-value \\
\hline ALB & 0.887 & $0.789-0.996$ & $0.043^{*}$ \\
CEA & 1.113 & $1.009-1.228$ & $0.032^{*}$ \\
$\begin{array}{l}\text { Tumor location } \\
\quad \text { Cardia and fundus of }\end{array}$ & - & - & $0.013^{*}$ \\
$\quad$ stomach & & - \\
Body of stomach & 6.920 & $0.585-81.856$ & 0.125 \\
Pyloric antrum & 10.733 & $0.840-137.107$ & 0.068 \\
Pyloric canal & 0.238 & $0.008-7.373$ & 0.413 \\
Ki-67 & 8.174 & $1.085-61.568$ & $0.041^{*}$ \\
\hline
\end{tabular}

* The asterisk indicates statistical significance

\# "cardia and fundus of stomach" was assigned as the reference in logistic regression analysis

\section{Discussion}

Here is a summary of our main findings. G-NET is rare and LNM plays an immense role in the prognosis [7]. However, current guidelines fail to provide relevant recommendation to the risk evaluation and management of LNM. European Neuroendocrine Tumor Society (ENETS) guidelines didn't provide relevant information in the 2012 version [8]. In the 2016 updated version, surgical treatment is recommended as the first-line strategy that follows strategies employed for gastric adenocarcinomas (partial or total gastrectomy with lymph node dissection) [9]. Similar recommendation was provided by the North American Neuroendocrine Tumor Society (NANETS) [10, 11]. In the 2017 NANETS guideline, metastatic G-NET are recommended to be treated in a similar fashion as other malignant carcinoids. National Comprehensive Cancer Network (NCCN) guidelines suggested that resection of gastrointestinal neuroendocrine tumors

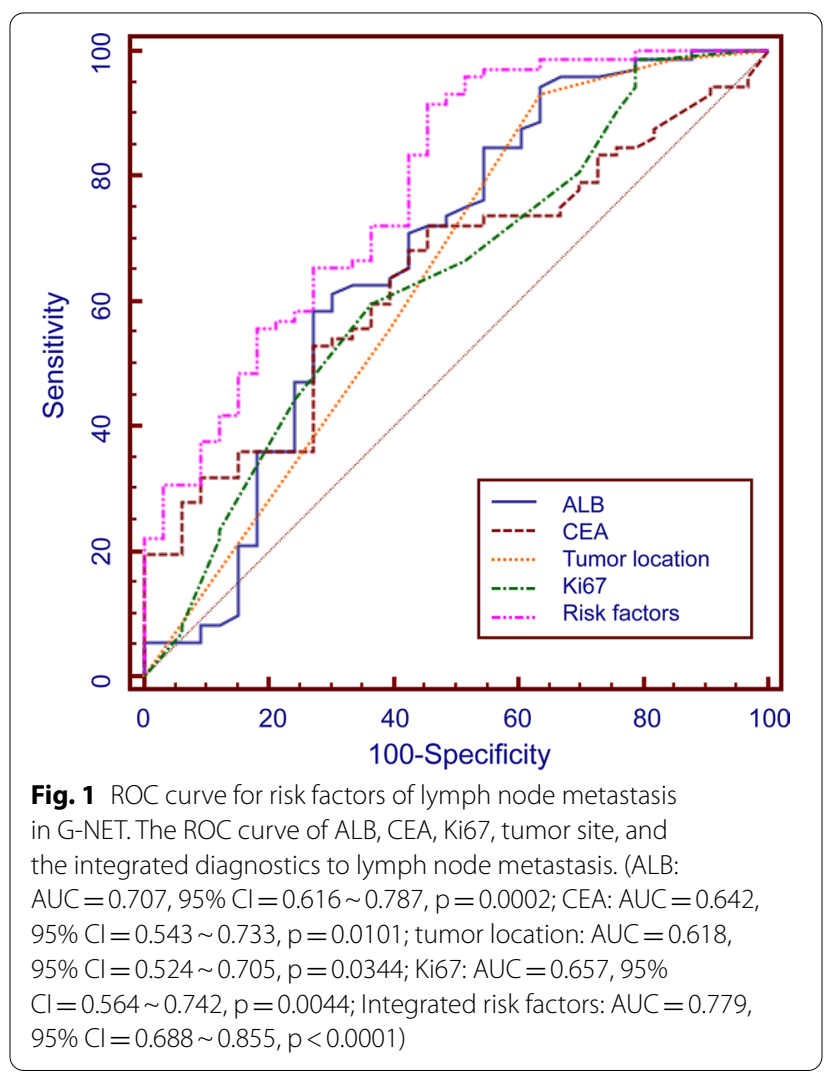

should include adequate regional lymph node resection [12]. However, in what situation lymph node resection is necessary and what kind of lymphectomy should be performed were not discussed. Chinese Clinical Oncology guidelines propounded that lymph node resection should be conducted for patients with distant metastasis, LNM or diagnosed as G3 grade [13]. In summary, current guidelines could not provide enough information for the management of G-NET with LNM. 


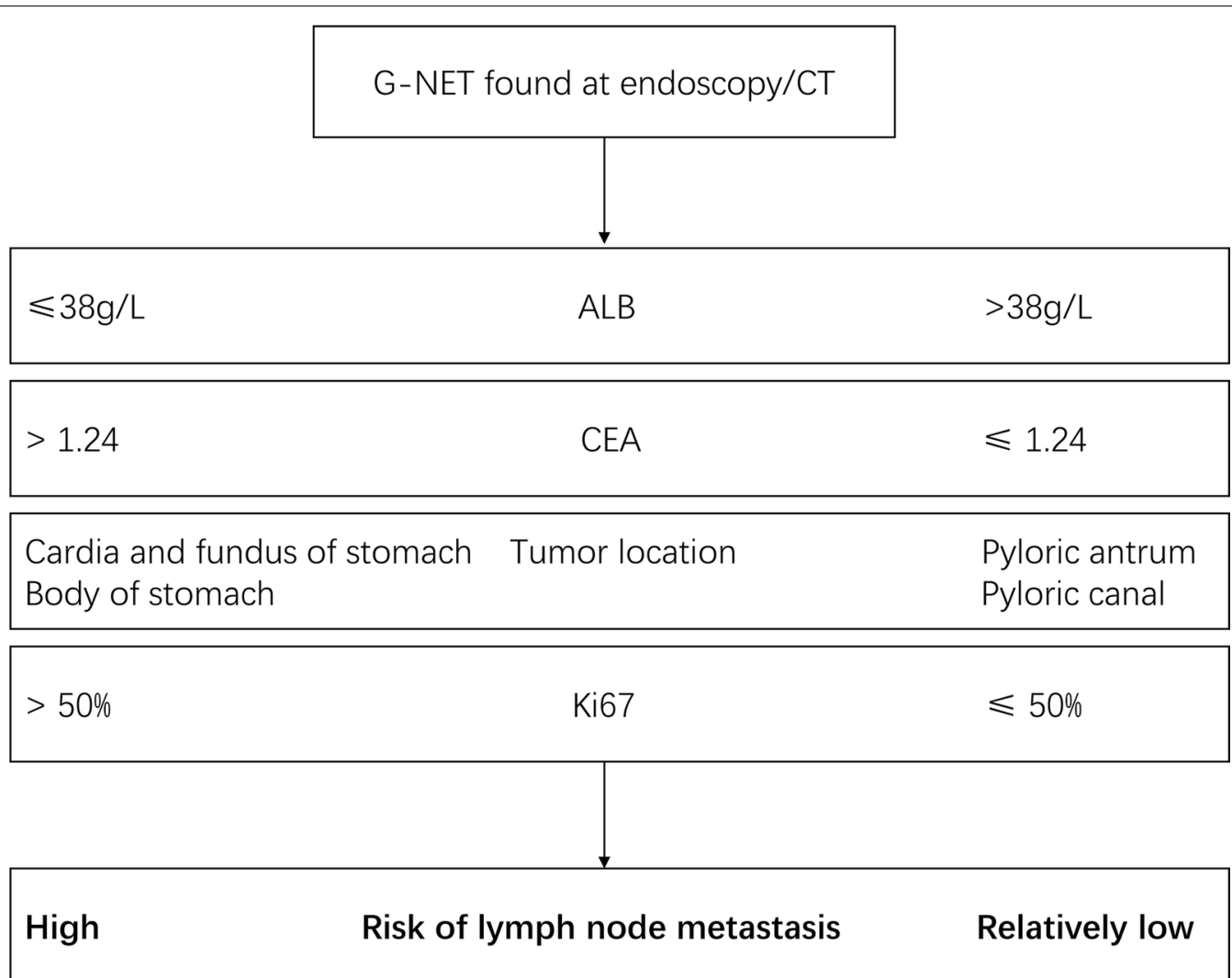

Fig. 2 Proposed approach for the risk evaluation of lymph node metastasis in G-NET. The cut-off values were extracted from previous ROC curve analysis

Moreover, it was difficult to fully exclude LNM before surgery.

By comparing G-NET patients with or without LNM, we found that older age, preoperative lower albumin level, higher CEA level, higher INR, longer TT, higher $\mathrm{Ki67}$, and CgA positive rate were associated with lymph node metastasis. Logistic regression identified that ALB, CEA, tumor location and Ki67 were independent risk factors for LNM in patients with G-NET. There has been an increasing incidence of G-NET in recent decades [14]. Surgical resection is the first-line recommendation for G-NET [15]. However, it is largely unknown how to determine the possibility of LNM preoperatively. Here, our study has provided useful information that ALB, CEA and Ki67 as well as tumor location are associated with the risk of LNM in G-NET.

As with other digestive NETs, our patients were divided into several groups according to the WHO G grade classification. Albeit $\mathrm{G}$ grade has exerted the versatile negative prognostic factor in digestive NETs from pancreas and jejunum-ileum, its diagnosis value for determining the prognosis of patients with G-NET didn't live up to expectation [16]. Likewise, the lack of solid evidence situated on the G grade effective on G-NET lymph node metastasis aroused our interest. However, resultant data retard the harnessing of $\mathrm{G}$ grade system to predict nodal metastasis. We sought to figure out risk factors with forecasted usage value to address this issue in this scenario.

Serum ALB level is an easily accessible laboratory indicator that reflects individual nutritional status. Previous study has demonstrated that albumin is a vital source of energy and amino acids for tumor cells, and it was increasingly absorbed by tumor cells owing to fast growth and active metabolism of tumors [17]. In addition, ALB is considered as an indicator of systemic inflammatory reaction in malignant tumors. G-NET potentially affects digestive and absorptive ability and is associated with systemic inflammatory response. Both reasons lead to suppressed synthesis of ALB, which was found more severe in G-NET patients with LNM [18]. A study involving 207 patients with malignant tumors reported that patients with lower prognostic nutrition index exhibited higher lymph node metastasis rate. Another retrospective study recruited 136 patients found that lymph node invasion was significantly correlated with ALB level [19]. Moreover, a scoring system named Glasgow prognostic 
score based on inflammation (CRP and ALB) has been validated as versatile in predicting progress for gastric cancer [20].

CEA is associated with various types of cancer including gastric cancer and correlated with overall survival of patients [21, 22]. A study in China found that increased CEA levels were associated with LNM in remnant gastric cancer [23]. Another study discovered that gastroenteropancreatic neuroendocrine neoplasm patients with elevated CEA, CA125 or CA19-9 exhibited worse overall survival [24]. Nevertheless, there were littele data about the relationship between CEA and LNM in NET. Our study found that elevated CEA could serve as a predicting factor of LNM in G-NET.

There were few studies discussing the correlation between tumor location and LNM in G-NET. Liang J et al. revealed that G-NET is mainly located in esophagogastric junction, most of which were aggressive malignant [25]. To our knowledge, our findings are the first investigation towards tumor location and LNM in G-NET. Our study has highlighted the tumor distribution in stomach associated with LNM manifestation in this specific cohort of patients. As for clinicians, LNM is worthy of more concern facing the G-NET patient whose tumor is located in cardia and fundus of stomach and body of stomach.

The nuclear antigen Ki67 structurally associated with chromatin helps determine tumor grade and prognosis [26]. Previous studies suggested a significant correlation between Ki-67 level and clinical outcome. Boo et al. revealed that higher Ki67 $(>60 \%)$ was associated with aggressive G-NET [27]. Another study illustrated that higher Ki67 was not only associated with higher $\mathrm{T}$ stage $(\mathrm{p}=0.003)$ but also tended to be associated with LNM $(\mathrm{p}=0.071)$ [28]. In accordance with previous reports, our study revealed that higher Ki67 could serve as an independent predictive factor for LNM in G-NET. When it comes to neuroendocrine tumors, Ki67 is the major prognostic factor and utilized in the novel grading system [29].

We are aware of potential limitations. First, this is a single-center retrospective study that may lead to selection bias. Second, since the short-term outcome between two groups was not significant and follow-up data is not fully available, we could not compare long-term outcomes of G-NET patients with or without LNM. Third, the rarity of G-NET and limited sample size hampers subgroup analysis such as distant metastasis compared to adjacent metastasis. In addition, molecular analysis was conducted in very few patients, which leads to failure of comparison of molecular features between LNM and non-LNM groups. Nevertheless, our study has provided a comprehensive exploration towards possible risk factors of LNM in G-NET. Future prospective studies are expected to provide more information for the identification of LNM in G-NET.

\section{Conclusion}

In conclusion, ALB, CEA, tumor location and Ki67 correlate with the risk of LNM in patients with G-NET.

\begin{abstract}
Abbreviations
LNM: Lymph node metastasis; G-NET: Gastric neuroendocrine tumor; WHO: World Health Organization; ALB: Preoperative albumin; CEA: Higher carcinoembryonic antigen; INR: International normalized ratio; TT: Thrombin time; Ki67: Tumor proliferation index; CgA: Chromogranin A; ROC: Receiver operation characteristic
\end{abstract}

\section{Acknowledgements}

Not applicable.

\section{Authors' contributions}

$M W, W G$, and $S L$ designed the research; XL, LS, and XFL collected the data; $X L, Z Y, S A$, and FS performed the data analysis; $X L$ wrote the manuscript; $M W$, WG, and SL reviewed the manuscript. All authors have read and approved this manuscript.

\section{Funding}

This work was supported by the National Natural Science Foundation of China (81602103) and the Natural Science Foundation of Jiangsu Province (BK20200052). The funding had no role in study design, collection, analysis or interpretation of data, or manuscript preparation.

\section{Availability of data and materials}

We declared that materials described in the manuscript, including all relevant raw data, will be freely available to any scientist wishing to use them for non-commercial purposes. The datasets used and analyzed during the current study are available from the corresponding author upon reasonable request without breaching participant confidentiality.

\section{Declarations}

Ethics approval and consent to participate

This study has been approved by the Ethics Committee of Nanjing Drum Tower Hospital (approval number: DTH-2020003A; approval date: Jan 06 2020). Informed consent is waived for this retrospective study by the Ethics Committees of Nanjing Drum Tower Hospital. We confirmed all methods were carried out in accordance with relevant guidelines and regulations.

Consent for publication

All authors agree to publish.

\section{Competing interests}

All authors have no conflict of interest.

\section{Author details}

${ }^{1}$ Department of Gastrointestinal Surgery, Nanjing Drum Tower Hospital, The Affiliated Hospital of Nanjing University Medical School, 321 Zhongshan RD, Nanjing 210008, China. ${ }^{2}$ Department of General Surgery, Beijing Friendship Hospital, Capital Medical University, Beijing 100050, China.

Received: 22 September 2020 Accepted: 23 March 2021

Published online: 31 March 2021

\section{References}

1. Modlin IM, Lye KD, Kidd M. A 50-year analysis of 562 gastric carcinoids: Small tumor or larger problem? Am J Gastroenterol. 2004;99(1):23-32. 
2. Coriat R, Walter T, Terris B, Couvelard A, Ruszniewski P. Gastroenteropancreatic well-differentiated grade 3 neuroendocrine tumors: review and position statement. Oncologist. 2016;21(10):1191-9.

3. Modlin IM, Lye KD, Kidd M. A 5-decade analysis of 13,715 carcinoid tumors. Cancer. 2003;97(4):934-59.

4. Azam-Zangeneh $\mathrm{H}$, Müller-Schilling M, Kandulski A. Neuroendokrine Neoplasien des Magens. Gastroenterologe. 2018;13(2):126-9.

5. Fendrich V, Bartsch DK. Surgical treatment of gastrointestinal neuroendocrine tumors. Langenbecks Arch Surg. 2011;396(3):299-311. https://doi. org/10.1007/s00423-011-0741-7.

6. Tang X, Chen Y, Guo L, Zhang J, Wang C. Prognostic significance of metastatic lymph node number, ratio and station in gastric neuroendocrine carcinoma. J Gastrointest Surg. 2015;19(2):234-41.

7. Chiramel J, Almond R, Slagter A, Khan A, Wang X, Lim KHJ, Frizziero M, Chakrabarty B, Minicozzi A, Lamarca A, et al. Prognostic importance of lymph node yield after curative resection of gastroenteropancreatic neuroendocrine tumours. World J Clin Oncol. 2020;11(4):13.

8. Delle Fave G, Kwekkeboom D, Van Cutsem E, Rindi G, Kos-Kudla B, Knigge U, Sasano H, Tomassetti P, Salazar R, Ruszniewski P. ENETS consensus guidelines for the management of patients with gastroduodenal neoplasms. Neuroendocrinology. 2012;95(2):74-87.

9. Delle Fave G, O'Toole D, Sundin A, Taal B, Ferolla P, Ramage JK, Ferone D, Ito T, Weber W, Zheng-Pei Z, et al. ENETS consensus guidelines update for gastroduodenal neuroendocrine neoplasms. Neuroendocrinology. 2016;103(2):119-24.

10. Kvols LK, Brendtro KL. The North American Neuroendocrine Tumor Society (NANETS) Guidelines: mission, goals, and process. Pancreas. 2010;39(6):705-6.

11. Strosberg JR, Halfdanarson TR, Bellizzi AM, Chan JA, Dillon JS, Heaney AP, Kunz PL, O'Dorisio TM, Salem R, Segelov E, et al. The North American Neuroendocrine Tumor Society Consensus Guidelines for surveillance and medical management of midgut neuroendocrine tumors. Pancreas. 2017:46(6):707-14.

12. Shah MH, Goldner WS, Halfdanarson TR, Bergsland E, Berlin JD, Halperin D, Chan J, Kulke MH, Benson AB, Blaszkowsky LS et al. NCCN Guidelines Insights: neuroendocrine and adrenal tumors, Version 2.2018. 2018, 16(6):693.

13. Chen L, Chen J, Zhou Z. Interpretation of the latest guidelines in the treatment of gastrointestinal neuroendocrine neoplasms. [Zhonghua wei chang wai ke za zhi] Chin J Gastrointest Surg. 2016;19(11):1201-4.

14. Crosby DA, Donohoe CL, Fitzgerald L, Muldoon C, Hayes B, O'Toole D, Reynolds JV. Gastric neuroendocrine tumours. Dig Surg. 2012;29(4):331-48.

15. Corey B, Chen H. Neuroendocrine tumors of the stomach. Surg Clin North Am. 2017:97(2):333.

16. Panzuto F, Boninsegna L, Fazio N, Campana D, Brizzi MP, Capurso G, Scarpa A, De Braud F, Dogliotti L, Tomassetti P, et al. Metastatic and locally advanced pancreatic endocrine carcinomas: analysis of factors associated with disease progression. J Clin Oncol. 2011;29(17):2372-7.
17. Sabrkhany S, Griffioen AW, Oude Egbrink MG. The role of blood platelets in tumor angiogenesis. Biochim Biophys Acta. 2011;1815(2):189-96.

18. Digant Gupta CGL. Pretreatment serum albumin as a predictor of cancer survival: a systematic review of the epidemiological literature. Gupta Lis Nutr J. 2019;2010(9):69.

19. Brewczynski A, Jablonska B, Pawlicki K. Associations between nutritional parameters and clinicopathologic factors in patients with gastric cancer: a comprehensive study. Nutr Cancer. 2017;69(5):752-61.

20. Crumley AB, McMillan DC, McKernan M, McDonald AC, Stuart RC. Evaluation of an inflammation-based prognostic score in patients with inoperable gastro-oesophageal cancer. Br J Cancer. 2006;94(5):637-41.

21. Fletcher RH. Carcinoembryonic antigen. Ann Intern Med. 1986;104(1):66-73.

22. Liu CX, Li XL. Stage-dependent changes in albumin, NLR, PLR, and AFR are correlated with shorter survival in patients with gastric cancer. Clin Lab. 2019;65(9):1623-33.

23. Wang WNR, Zhou Z. Risk factor analysis and prediction model establishment of lymph node metastasis in remnant gastric cancer. Zhonghua Wei Chang Wai Ke Za Zhi. 2018;21(5):541-5.

24. Chen L, Zhang Y, Chen M, Chen J. Prognostic value of carcinoembryonic antigen, alpha fetoprotein, carbohydrate antigen 125 and carbohydrate antigen 19-9 in gastroenteropancreatic neuroendocrine neoplasms. [Zhonghua wei chang wai ke za zhi] Chin J Gastrointest Surg. 2017;20(9):1002-8.

25. Liang J, Liu S. Clinicopathological features of the primary gastric neuroendocrine neoplasms. [Zhonghua zhong liu za zhi] Chin J Oncol. 2014:36(7):522-8

26. Modlin IM, Oberg K, Chung DC, Jensen RT, de Herder WW, Thakker RV, Caplin M, Delle Fave G, Kaltsas GA, Krenning EP, et al. Gastroenteropancreatic neuroendocrine tumours. Lancet Oncol. 2008;9(1):61-72.

27. Boo YJ, Park SS, Kim JH, Mok YJ, Kim SJ, Kim CS. Gastric neuroendocrine carcinoma: clinicopathologic review and immunohistochemical study of E-cadherin and Ki-67 as prognostic markers. J Surg Oncol. 2007:95(2):110-7.

28. Lee HE, Mounajjed T, Erickson LA, Wu TT. Sporadic gastric well-differentiated neuroendocrine tumors have a higher Ki-67 proliferative index. Endocr Pathol. 2016;27(3):259-67.

29. Panzuto F, Nasoni S, Falconi M, Corleto VD, Capurso G, Cassetta S, Di Fonzo M, Tornatore V, Milione M, Angeletti S, et al. Prognostic factors and survival in endocrine tumor patients: comparison between gastrointestinal and pancreatic localization. Endocr Relat Cancer. 2005;12(4):1083-92.

\section{Publisher's Note}

Springer Nature remains neutral with regard to jurisdictional claims in published maps and institutional affiliations.
Ready to submit your research? Choose BMC and benefit from:

- fast, convenient online submission

- thorough peer review by experienced researchers in your field

- rapid publication on acceptance

- support for research data, including large and complex data types

- gold Open Access which fosters wider collaboration and increased citations

- maximum visibility for your research: over $100 \mathrm{M}$ website views per year

At BMC, research is always in progress.

Learn more biomedcentral.com/submissions 